\title{
Oil and grease (O\&G) removal from commercial kitchen waste water using carbonised grass as a key media
}

\author{
Siti Nazahiyah Rahmat ${ }^{1, a}$, Ahmad Zurisman Mohd Ali ${ }^{1}$, Mohd Haziman Wan Ibrahim ${ }^{1}$ and Nur Azrena Alias ${ }^{1}$ \\ ${ }^{1}$ Faculty of Civil and Environmental Engineering, Universiti Tun Hussein Onn Malaysia (UTHM), Batu Pahat, Johor, Malaysia
}

\begin{abstract}
Oil and grease $(O \& G)$ are usually found in kitchen waste water. $O \& G$ are poorly soluble in water and can cause serious problems during the wastewater treatment. Adsorption is a fundamental process in the treatment of kitchen waste water and very economical. Activated carbon is the most effective adsorbent for this application. Therefore, the aim of the current study is to determine the potential of four materials (i.e. sand, gravel, carbonised grass (CG) and clay powder) as filter media for O\&G removal. The CGs were originated from "Elephant Grass" and it is a fast growing plant with significant potential as carbon. The clay acts as a magnet, drawing the oil molecules out of the water and causing them to attach to the surfaces of the clay. In the current study, two filters were developed with different media materials to get the best percentage removal. Filters 1 and 2 were filled with sand, gravel and $\mathrm{CG}$, and sand, gravel, CG and powder clay, respectively. Three samples were taken during peak hour between April and May 2016. The initial O\&G concentration varied from $101.37 \mathrm{mg} / 1$ to $248.30 \mathrm{mg} / 1$ and the final concentration varied from none to $22.57 \mathrm{mg} / 1$ for both filters. The percentage removal (\%) of O\&G were between 90.9 and 97.3 (Filter 1) and between 94.3 and 100 (Filter 2). Overall, both filters could efficiently remove O\&G in the waste water and the quality of the carbonised grass proved to be as good as carbon produced from other traditional sources.
\end{abstract}

\section{Introduction}

Commercial kitchen waste water refers to any release to the sewerage system from the restaurants and other commercial food service facilities which varies significantly from residential waste water. When commercial kitchen reaches its peak operating hours, the waste water produced is much higher than the wastewater produced by the residential wastewater. This is due to the waste water consists higher level of oil and grease (O\&G). Most of O\&G are insoluble in water, thus will float on the water surface, due to the lower specific gravity than the water. Large amounts of oil and grease in the waste water will cause trouble in the collection system pipes. If not disposed of properly, O\&G builds up in the sewer system constricting flow, which could cause sewer back-ups into homes. Additionally, it may hinder sewage treatment processes [1].

Many methods have been applied for the separation of $O \& G$, including a variety of filters [2], reverse osmosis, gravity separation, biological processes [3], air flotation [4,5], membrane bioreactor, chemical coagulation, and electrocoagulation [6]. One commonly used technique and has gained wide attention for removing organics dissolved in water is the process of adsorption. It involves the separation of substances from one phase to the surface of another. The adsorbing phase is the adsorbent, and the material concentrated or adsorbed at the surface of that phase is the adsorbate [7]. The process is efficient and there are many waste materials that can be used as adsorbents.

Clay and carbon are among several adsorbents used in the adsorption method [8]. Carbons are used extensively as adsorbent for separation of contaminants due to its simplicity and has proven to be technically feasible [2]. Clays have been successful in removing oil-grease from wastewater streams [9]. CG media is produced by crushing the raw material to the correct size. The carbon-based material is converted to carbon by thermal decomposition in a furnace using a controlled atmosphere and heat. It is realised that wastes are unutilized resources. A number of studies have been carried out to produce CG such as bagasse [10], sugarcane bagasse [11], rice husks [12, 13] and coconut shells [14]. Goorahoo et al. [15] proposed that Elephant grass appears to have significant potential for scavenging excess soil, nitrogen and phosphorus and can be very useful in a filtration system. However, studies on the utilisation of grass as a source of CG are still very limited and so the current work may likely to get attention from researchers working on environmentalists.

Clay has been widely used because of their strong sorption and complexation ability [16]. It can remove approximately $70 \%$ of the waste of water in a water

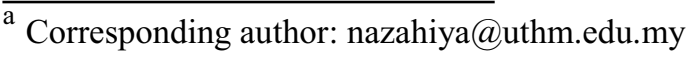


removal system. Therefore, the objectives of this study are threefold: (i) to investigate the quality of O\&G released from the commercial kitchen, (ii) to propose filters that can treat and remove O\&G using $\mathrm{AC}$ as a principal media, and (iii) to measure the efficiency of the proposed filters.

\section{Materials and methods}

\subsection{Study Area}

Parit Raja is a town in Batu Pahat District, Johor. It is located approximately $23 \mathrm{~km}$ away from Bandar Penggaram, Batu Pahat (the capital of the district) (see Figure 1). Along to Parit Raja, there are many villages and most of them are name after a Parit, as a result of relatively flat terrain and abundant waterways. In recent years, due to the development and rapid expansion of Universiti Tun Hussein Onn Malaysia (UTHM), the town has seen substantial growth. There is increasing number of commercial areas including restaurants and food stalls along the way to the city. In the current study, the location of sampling point was in Parit Daun, Parit Raja.

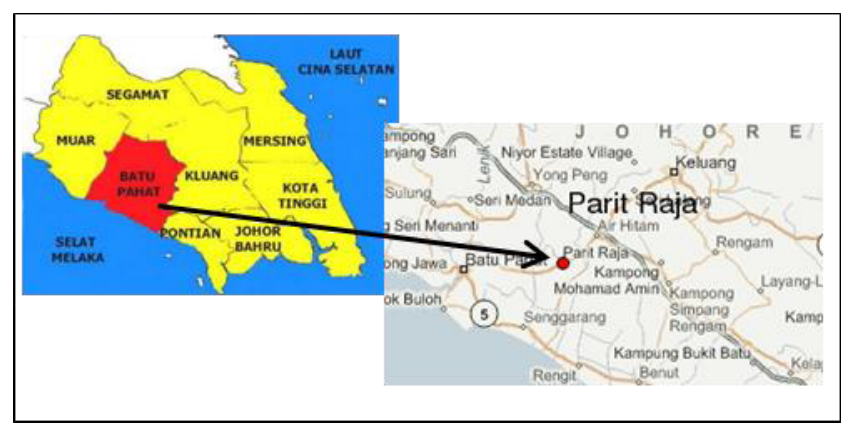

Figure 1. Location of the study site

\subsection{Water Sampling}

The water quality of the Parit Raja, one of the most densely populated areas within the region, is significantly degraded due to human activities as well as urbanization. In the current study, the waste water was released from a single discharge of the commercial kitchen at Parit Daun, thus, it is known as point source of pollution (see Figure 2).

The sampling was carried out between April 2016 and May 2016 (Table 1). The sampling days were scheduled such that they covered rainy and non-rainy days. A total of 3 samples were investigated. Samples were collected manually using a polyethylene bottle. To analyse, a volume of $1.5 \mathrm{~L}$ water sample for each time of sampling was filled into the bottle.

Table 1. Characteristics of monitored samples

\begin{tabular}{cccc}
\hline Sample & $\begin{array}{c}\text { Sampling } \\
\text { Date }\end{array}$ & $\begin{array}{c}\text { No. of dry } \\
\text { days }\end{array}$ & $\begin{array}{c}\text { Rainfall } \\
(\mathrm{mm})\end{array}$ \\
\hline Sample 1 & $28 / 4 / 2016$ & 2 & 0 \\
Sample 2 & $2 / 5 / 2016$ & - & 5 \\
Sample 3 & $11 / 5 / 2016$ & - & 13 \\
\hline
\end{tabular}

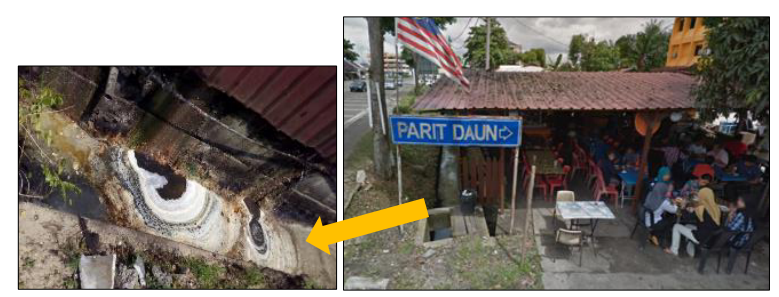

Figure 2. Image of the drainage at the study area.

\subsection{Filters}

Two filters with different types of media were developed. Apart of sand and gravel for filter media, $\mathrm{CG}$ and clay were also used. The preparation of these media are as follows:

\subsubsection{Carbonised grass}

Carbonised grass was selected as the principal filter media. These carbons were originated from Pennisetum Purpureum (Figure 3) or also known as 'Elephant Grass'. Elephant grass requires very little supplementary nutrients for growth and can be harvested up to four times a year, which makes this plant one of the most prospective crops for energy use [15].

Elephant grass leaves were washed with deionized water to remove adhering dirt particles from the surface and dried at $110^{\circ} \mathrm{C}$ for $24 \mathrm{~h}$, Dried leaves were cut and loading into a furnace and heated up to $700^{\circ} \mathrm{C}$ for 6 hours. The furnace lid was left closed as much as possible during the process to avoid the leaves turn into ash.

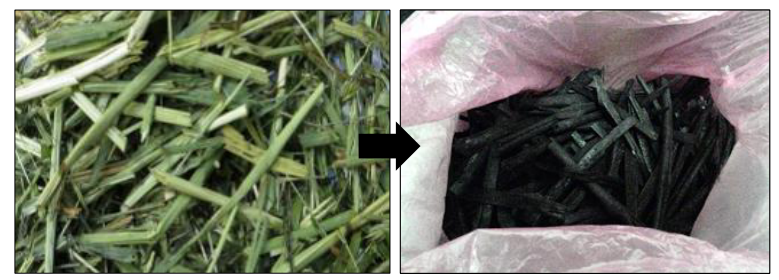

Figure 3. Carbon from Elephant Grass.

\subsubsection{Clay}

Apart from CG, clay is another adsorbent used in the adsorption technique [9]. In the current study, the clay sample was obtained from a factory located in Ayer Hitam, Johor. The clay was broken up into smaller pieces and loading into a crusher machine to get the clay powder (see Figure 4). 


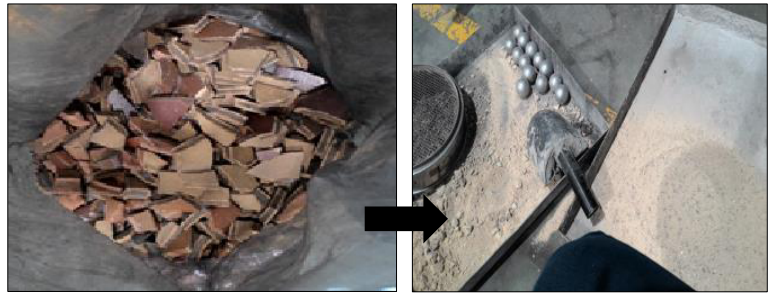

Figure 4. Powder clay used in the filter.

\subsubsection{Dimensions}

Two buckets were used to construct the frame of the filter. They are identical and measure $0.5 \mathrm{~m}$ in height and $0.3 \mathrm{~m}$ in diameter. The following descriptions of the design begin with the left bucket continue to the right and in the same direction as the flow of waste water (Figure 5). For Filter 1, there are $90 \mathrm{~mm}$ of sand and beneath the sand, there are $75 \mathrm{~mm}$ of gravel. Waste water passes through the holes and into the second bucket. In the second bucket, there are $20 \mathrm{~mm}$ of CG, $85 \mathrm{~mm}$ of sand and $50 \mathrm{~mm}$ of gravel (Figure 5a). For Filter 2, in the first bucket there are $90 \mathrm{~mm}$ of sand 75 $\mathrm{mm}$ of gravel. In the second bucket, there are $20 \mathrm{~mm}$ of $\mathrm{CG}, 20 \mathrm{~mm}$ of clay, $65 \mathrm{~mm}$ of sand and $50 \mathrm{~mm}$ of gravel (Figure 5b). A plastic spigot is attached to the outer side of the bucket to release the water.

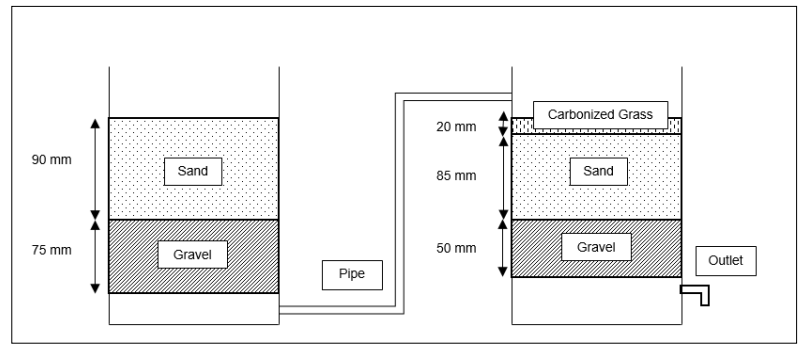

(a) Filter 1

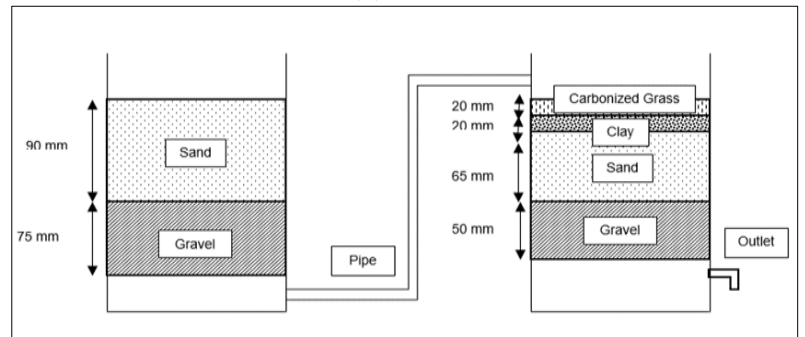

(a) Filter 2

Figure 5. Dimensions of the filters.

For each run, $1500 \mathrm{ml}$ of sample was poured into the filter and the amount of time required for the samples to infiltrate was measured to determine the flow rate.

\subsection{Waste water quality analysis}

Samples were collected prior to and after infiltration to compare the concentration of O\&G that have passed through the medium. Water samples were sent to the
Micro-pollutant Research Centre (MPRC) and Waste Water Engineering Laboratory, UTHM for analysis within 24 hours after sampling. The laboratory analysis followed the Standard Methods for the examination of water and wastewater [17].

$50 \mathrm{~mL}$ of acidified waste water was transferred to a separatory funnel. $50 \mathrm{~mL}$ of petroleum ether were then added to the funnel and the funnel was shaken vigorously for 2 minutes. The lighter waste water layer will be on the top and heavier petroleum ether layer will be on the bottom. The bottom layer of petroleum ether was drained into a clean and dried flask. The contents of the flask were then heated so that the petroleum ether was distilled into another container. The flask (containing the extracted $\mathrm{O} \& \mathrm{G})(A)$ was reweighed. The original weight of the flask $(B)$ was subtracted and the total O\&G was calculated (see Equation 1).

$$
\text { Value of } 0 \& \mathrm{G}=\frac{(A-B) \times 1000}{\text { ml sample }}
$$

$A$ is the weight of flask plus with residue $(m g)$ and $B$ is the weight of flask $(\mathrm{mg})$.

\section{Results and discussion}

\subsection{Flow measurement}

Flow rate is the time taken for the solvent to flow through the natural sorbent. The longer the contact time, the more the amount of organic material can be exposed to the adsorbent, causing in a more effective adsorption process.

The flow rate for each filter was calculated by measuring the volume of wastewater samples and time taken for the waste water flows through the media to the outlet. The measurement was determined using the bucket and stopwatch method. The volume of the bucket divided by the time taken to fill up the bucket produces the value of the flow. For Filters 1 and 2, the flow rates measured were $0.3 \mathrm{~L} / \mathrm{s}$ and $0.001 \mathrm{~L} / \mathrm{s}$, respectively. Flow rate in Filter 2 was slower than Filter 1 due to the clay powder in the filter which had been slowing down the process. It is noted that the lower the flow rate, the more time the O\&G be adsorbed.

\subsection{O\&G Removal Efficiency}

Water samples were taken on $28^{\text {th }}$ April 2016, $2^{\text {nd }}$ May 2016 and $5^{\text {th }}$ May 2016 by applying the grab technique. Table 2 shows the concentration values before and after the treatment for both filters. Sample 1 gives the highest initial concentration of $O \& G$ of $248.3 \mathrm{mg} / \mathrm{l}$ due to the sampling during dry day. Referring to Table 1, the observed antecedent dry days is 2 days. The concentration of $\mathrm{O \& G}$ in the waste water is at its highest due to the accumulated pollutants including O\&G since the preceding event. While for Samples 2 and 3 , the initial concentrations are 101.37 and 205.48, respectively. These results could be associated with the 
O\&G that retained deposited in the drains during dry days and become diluted during storms.

For all samples, the O\&G concentrations reduced from $248.3 \mathrm{mg} / 1$ to $22.57 \mathrm{mg} / 1$ (Sample 1$), 101.37 \mathrm{mg} / 1$ to $2.74 \mathrm{mg} / \mathrm{l}$ (Sample 2), $205.48 \mathrm{mg} / \mathrm{l}$ to $9.45 \mathrm{mg} / \mathrm{l}$ (Sample 3) after being filtered through Filter 1. While for Filter 2, the concentrations were reduced tremendously for all samples from $248.3 \mathrm{mg} / 1$ to 3.72 $\mathrm{mg} / \mathrm{l}$ (Sample 1), $101.37 \mathrm{mg} / \mathrm{l}$ to none (Sample 2) and $205.48 \mathrm{mg} / \mathrm{l}$ to $1.44 \mathrm{mg} / \mathrm{l}$ (Sample 3 ). These results show evidence the ability of the medium to remove the O\&G.

$\mathrm{pH}$ of individual sample was also measured immediately after its collection. The initial $\mathrm{pH}$ of wastewater samples is generally towards acidic side. It is as low as 5.76 and as high as 6.55 before treatment (see Table 2). For both filters, the $\mathrm{pH}$ values after treatment ranging from 5.97 to 7.32. The media used in the filters (i.e. activated carbon and clay) absorbed some minerals, thus causing the changes in $\mathrm{pH}$. The carbon itself can act as an ion exchange type media and contribute to $\mathrm{pH}$ rise.

Table 2. Concentrations of O\&G and $\mathrm{pH}$ values.

\begin{tabular}{ccccc}
\hline \multirow{2}{*}{ Parameter } & \multirow{2}{*}{ Sample } & \multirow{2}{*}{ Unfiltered } & \multicolumn{2}{c}{ Filtered } \\
\cline { 4 - 5 } & & & Filter 1 & Filter 2 \\
\hline \multirow{2}{*}{ O\&G } & Sample 1 & 248.30 & 22.57 & 3.72 \\
$(\mathrm{mg} / \mathrm{l})$ & Sample 2 & 101.37 & 2.74 & 0.00 \\
& Sample 3 & 205.48 & 9.45 & 1.44 \\
\hline \multirow{2}{*}{$p H$} & Sample 1 & 5.87 & 6.34 & 7.13 \\
& Sample 2 & 6.55 & 7.14 & 7.32 \\
& Sample 3 & 5.76 & 5.97 & 6.39 \\
\hline
\end{tabular}

From the observation, when the water sample was poured into the filter, there is still a slight sheen of oil and grease at the bottom of the first bucket. After flowing through the second bucket, it can be seen that the $O \& G$ retained at the carbonised grass layer and hence resulted in the removal of O\&G. Image of the samples before and after the treatment is shown in Figure 6. It can be clearly seen that the sample after filtration using Filter 1 is very clear. In contrast, the water in Filter 2 is brownish in colour and very turbid due to the presence of clay powder.

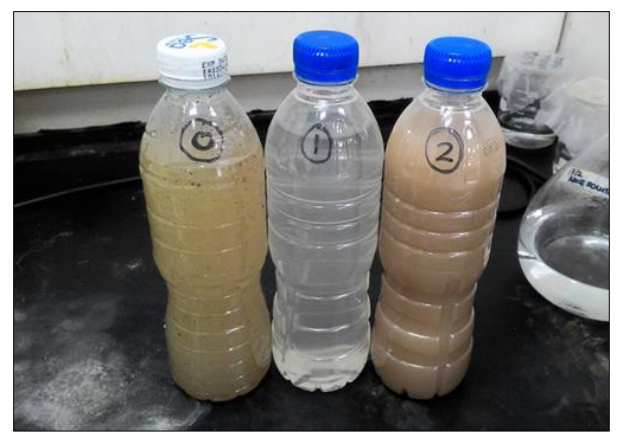

Figure 6. Waste water samples $(0)$ untreated, and treated using (1) Filter 1 and (2) Filter 2.

The percentage removal was also calculated to get the efficiency of the filters (see Figure 7). The results show that for all samples, Filter 1 could remove from $90.9 \%$ to $97.3 \%$ of O\&G. While for Filter 2, for all samples, the percentage removal ranges from $94.3 \%$ to $100 \%$. It is observed that for Sample 2, after passing the filter, the water is free from O\&G.

From these results, it can be concluded that the materials tested can all be used as filter media material. Sand, gravel, CG and clay powder provided the best removal efficiency. Clay powder may be best used as an additive, however, in the future it is recommended not to use it in a powder form. This will slightly reduce the turbidity of water.

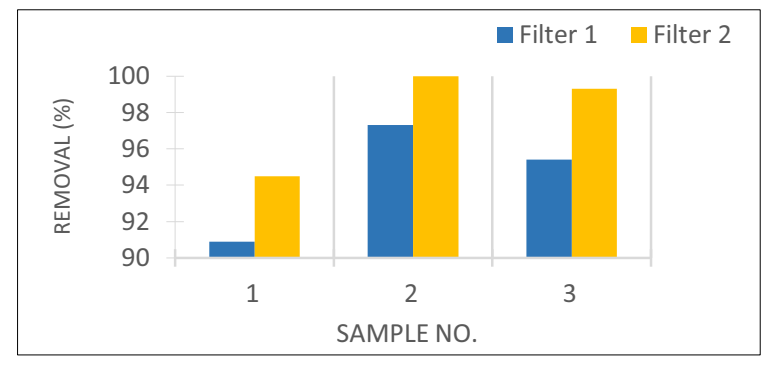

Figure 7. Percentages of O\&G removal for both filters.

\section{Conclusions and Recommendations}

The current study determined the potential of four media for O\&G removal which were sand, gravel, carbon and clay. Using carbon and clay could benefit us in terms of cost and also reassuring the sustainable use of waste materials. The work shows how environmental wastes could be a useful source of obtaining novel engineering material like carbon. In the present work grasses are considered as a safer, cheaper and greener way of utilizing them as a source of preparing carbon.

The initial concentrations of O\&G in waste water were quite high ranged from $101.37 \mathrm{mg} / \mathrm{l}$ to $248.3 \mathrm{mg} / \mathrm{l}$. The results showed that the waste water was discharged directly into the drainage system. In the current study, both filters could assist with O\&G removal as the percentage removal recorded was between $90.9 \%$ and $100 \%$.

Based on the findings of this study, several areas are identified that can be improved. Recommendations for future studies are summarised as follows:

1. A more intensive waste water monitoring is recommended to get more accurate and reliable results.

2. An important issue to be addressed is the influence of length of dry period and rainfall intensity on the water quality.

3. The clay used should not be in a powder form as the clay will disperse thus turning the water into brownish colour and slowing down the process of filtration.

4. Further analysis is carried out to study on the amount of water treated between maintenance intervals if the filter is going to be developed. This filter will be installed under the kitchen sink and the water quality will be monitored. This filter is expected to be a potential option to treat commercial kitchen waste water. 


\section{Acknowledgements}

The authors are grateful for the funding provided by the Universiti Tun Hussein Onn Malaysia (Vote U418) in support of this research.

\section{References}

1. M.A. Fulazzaky and R. Omar, Removal of oil and grease contamination from stream water using the granular activated carbon block filter, Clean Techn Environ Policy, 14, 965-971, (2012).

2. K. Okiel, M. El-Sayed and M. Y. El-Kady, Treatment of oil-water emulsions by adsorption onto activated carbon, bentonite and deposited carbon, Egyptian Journal of Petroleum, 20 (2), 9-15, (2011).

3. J.C. Campos, R.M.H. Borges, A.M. Filha and N.R. Oliveira, Water Research, 36, 95-104, (2002).

4. B. Tansel, and B. Pascual, Removal of emulsified fuel oils from brackish and pond water by dissolved air flotation with and without polyelectrolyte use: pilot scale investigation for estuarine and near shore applications, Chemosphere, 85 (7), 1182-1186, (2011).

5. A.A. Sharmani, A. James and H. Xiao, Destabilisation of oil-water emulsions and separation by dissolved air flotation, Water Research, 36, 1503-1512, (2002).

6. W. Scholz and W. Fuchs, Treatment of oil contaminated wastewater in a membrane bioreactor, Water Research, 34 (14) 3621-3629, (2000).

7. L. Frank Slejko, Adsorption Technology a Step-byStep Approach to Process Evaluation and Application, Marcel Dekker, Inc., New York and Basel, (1985).

8. R.M. Zakaria, I. Hassan, M.Z. El-Abd, Y.A. ElTawil, Lactic acid removal from wastewater by using different types of activated clay. In: Thirteenth international water technology conference (IWTC), Hurghada, 13, 403-416, (2009).

9. A.O. Alade, A.T. Jameel, A. S. Muyubi, M. I. Abdul Karim \& M. D. Z. Alam, Removal of oil and grease as emerging pollutants of concern (EPC) in wastewater stream. Iranian Journal of Oil \& Gas Science and Technology, 2(4), 01-11, (2011).

10. V. Minkova, S.P. Marinov, R. Zanzi, E. Bjornbom, T. Budinova, M. Stefanova, et al., Thermochemical treatment of biomass in a flow of steam or in a mixture of steam and carbon dioxide, Fuel Proc. Technol. 62, 45, (2000).

11.E. Cetin, B. Moghtaderi, R. Gupta, T.F. Wall, Influence of pyrolysis conditions on the structure and gasification reactivity of biomass chars, Fuel, 83, 2139, (2004).

12.P.K. Malik, Use of activated carbons prepared from sawdust and rice-husk for adsorption of acid dyes: a case study of Acid Yellow 36, Dyes Pigments, 56, 239, (2003).

13. N. Yalcin, V. Sevinc, Studies of the surface area and porosity of activated carbons prepared from rice husks, Carbon, 38, 1943, (2008).
14. M. Osava, Elephant Grass for Biomass. Inter Press Service News Agency, October 10, (2007).

15.D. Goorahoo, F. Cassel, D, Adhikari and M. Rothberg, Update on elephant grass research and its potential as a forage crop, California Alfalfa and Forage Symposium. UC Cooperative Extension, Agronomy Research and Extension Center, Plant Sciences Department, University of California, Davis, Visalia, CA, (2005).

16. G. Sheng, H. Dong, Y. Li, Characterization of diatomite and its application for the retention of radiocobalt: role of environmental parameters, J. Environ. Radioactiv. 113, 108-115, (2012).

17. American Public Health Association, APHA, Standard methods for the examination of water and wastewater, 19th edn. APHA, Washington DC, (1995). 